\title{
Javno zasebno partnerstvo v zdravstvu
}

UDK: 334.012.36:61(045)

\author{
Elda Gregorič Rogelj \\ Ministrstvo za zdravje RS \\ elda.gregoric-rogelj@gov.si
}

\begin{abstract}
IZVLEČEK
Prispevek obravnava javno zasebno partnerstvo (JZP) z vidika mešanega javno zasebnega zdravstva v Sloveniji ob upoštevanju ekonomskih pogojev, zakonodaje za področje javnih zavodov, značilnosti, prednosti in slabosti, kot jih ugotavljajo v okoljih z izkušnjami s tovrstnim načinom izvajanja projektov na področju zdravstva.

Prikazane so mogoče oblike sodelovanja v zdravstvu, najpogostejši modeli JZP v bolnišnicah in navedene izkušnje z JZP v nekaterih državah z daljšo tradicijo tovrstnih oblik izvajanja projektov v zdravstvu. Za investicijska vlaganja $v$ zdravstvene zmogljivosti javnofinančni viri niso zadostni, zato so nekateri zdravstveni zavodi v Sloveniji pristopili k pripravi ali izvedbi projektov v JZP. V prispevku so obravnavani primeri JZP v SB Brežice, OZ Gorenjske, Bolnišnici Sežana in IRI Ljubljana.
\end{abstract}

Ključne besede: javno zasebno partnerstvo, zdravstveno varstvo, investicijska vlaganja, zdravstveni zavodi

JEL: 119

\section{Javno zasebno partnerstvo $v$ zdravstvu - priložnosti in izkušnje}

Javno zasebno partnerstvo ( $v$ nadaljevanju: JZP) so različne oblike sodelovanja med javnimi organi in poslovnim svetom s ciljem zagotavljanja zasebne pobude za financiranje, upravljanje, vzpostavitev, prenovo, vodenje in vzdrževanje infrastrukture, oziroma za izvajanje javnih storitev. Značilnost javno zasebnega partnerstva so dolgoročne pogodbe ter delitev tveganja in učinkov poslovanja. Po vsebini so projekti JZP povezani z zasebnimi vlaganji v javne projekte, lahko pa tudi pomenijo javno financiranje zasebnih projektov, ki so $\vee$ javnem interesu. JZP kot oblika strateškega partnerstva med institucijami javnega 
Elda Gregorič Rogelj

Javno zasebno partnerstvo v zdravstvu

in zasebnega sektorja lahko uspešno prispeva k zmanjšanju javnih izdatkov za javne storitve in k ohranjanju dosežene ravni javnih storitev, če so ustrezno opredeljeni vsebina sodelovanja, tveganje in drugi pogodbeni odnosi med javnim in zasebnim partnerjem ter je preverjen javni interes. (Mužina, 2007, str.30)

Na področju zdravstvenega varstva Svetovna zdravstvena organizacija podaja definicijo JZP, ki opisuje partnerstvo kot sredstvo za povezovanje javnega in zasebnega partnerja, zaradi cilja izboljšanja zdravja prebivalstva na podlagi sporazumno določenih vlog in principov. Vzdrževanje ravnotežja moči med posameznimi stranmi je bistvenega pomena, pri čemer mora sodelovanje slediti ciljem doseganja javnega zdravja, enakomerni dostopnosti do zdravstvenih storitev in preprečevati poslabšanje zdravja prebivalstva. (Buse\&Walt, 2000, Global public-private partnerships: part I-a new development in health?)

$\checkmark$ teoriji so razvidne številne prednosti JZP, ki navajajo sodelovanje $z$ zasebnim sektorjem zaradi zagotavljanja prednosti, kot so zasebna sredstva in vlaganja $\vee$ projekte $\vee$ javnem interesu, znanja (know-how) in upravljalske izkušnje ter z njimi povezana učinkovitost. $V$ praksi je zelo pogosto glavni namen JZP razbremeniti proračun in zmanjšati zadolževanje. JZP lahko neposredno zmanjša trenutne javne izdatke z izvajanjem javnih storitev z nižjimi stroški, zmanjša stroške za investicijska vlaganja $v$ javni sektor ter lahko oblikuje nove vire prihodkov javnemu sektorju, če gre za določene projekte $v$ infrastrukturo (Loxley, J. \& J. Loxley, A., 2007, str. 267-276).

Po drugi strani pridobljene izkušnje z izvajanjem projektov $\vee$ JZP vse pogosteje izpostavljajo slabosti JZP. Nikakor ni nujno, da so storitve $\vee$ primeru uporabe JZP cenejše, pogosto so dražje, kljub ekonomičnemu poslovanju, kar naj bi bilo pogojeno z razlogom, da ob večji preglednosti stroškov uporabnik plača tudi tiste, ki so bili predhodno pokriti iz javnih sredstev. Med glavnimi slabostmi JZP se navajajo zmanjšanje nadzora javnega sektorja pri zagotavljanju storitev, tveganje, povezano z neizkušenostjo javnega sektorja, nejasna razdelitev odgovornosti in s tem tveganje za oba sektorja, odpor javnosti do zasebnega kapitala, možnost dražjega kreditiranja zasebnikov $\vee$ primerjavi s kreditiranjem države ter pristranskost pri izbiri zasebnega partnerja (Mužina, 2005, str. 15).

Izvajanje zdravstvenega varstva $\vee$ vseh okoljih zajema številne oblike javno zasebnega sodelovanja, zato ima $s$ tega vidika JZP $\vee$ zdravstvu dolgotrajno tradicijo. $\vee$ državah s pretežno javnim sistemom zdravstvenega varstva zagotavlja zasebni sektor pomemben del "inputov", kot so farmacevtski proizvodi, medicinsko tehnični pripomočki, oprema ter različne podporne storitve. $V$ državah $s$ 
Elda Gregorič Rogelj

Javno zasebno partnerstvo v zdravstvu

pretežno zasebnim lastništvom zdravstvene infrastrukture država posega $v$ sistem zdravstvenega varstva $z$ regulacijo in finančnimi vzpodbudami. Posebej $v$ bolnišnicah se kaže ta potreba zaradi izvajanja nekih dejavnosti, kot so raziskovalna dejavnost, učni proces in razvojni programi.

V svetu se je po letu 1980 privatizacija javnih storitev, vključno z zdravstvenimi, občutneje razširila, sklicujoč se na sporazumno sprejeti cilj zmanjševanja vloge države $v$ javni sferi. Na področju zdravstva zasledimo izkušnje z JZP in modele JZP zlasti po letu 1980 za področje bolnišničnega zdravstvenega varstva $\vee$ evropskih državah, kot npr. $\vee$ Veliki Britaniji, Španiji, Portugalski, Avstriji, Nemčiji, Grčiji, Italiji, pa tudi $\vee$ Avstraliji, ZDA in Kanadi. Poudarek na oblikah in modelih JZP $\vee$ bolnišničnem zdravstvenem varstvu je mogoče pripisati dejstvu, da so na primarni ravni zdravstvene dejavnosti $\vee$ teh okoljih drugačna organiziranost in statusne oblike.

Sodelovanje javnega sektorja z zasebnim na področju bolnišnične dejavnosti se po mnenju številnih avtorjev obravnava kot področje, kjer je zasebna pobuda koristna in kjer JZP lahko pomembno vpliva na nadzorovanje stroškov in izboljšanje kakovosti storitev $s$ sodelovanjem $v$ segmentu gradnje in upravljanja javnih bolnišnic. Možnosti za vključitev zasebnega sektorja so različne in zelo razvejane, od oddajanja podpornih dejavnosti zunanjim izvajalcem (outsourcing) vse do privatizacije z odprodajo kapacitet ter s številnimi možnostmi med navedenima, kar prikazuje Tabela1. Različne možnosti sodelovanja zasebnega sektorja se razlikujejo glede na to, kako se vključuje zasebni sektor, lahko pa zagotavlja upravljanje medicinskih storitev, ima v lasti ali daje $\vee$ postopen odkup bolnišnične zmogljivosti, zaposluje osebje in financira ter upravlja investicije (povzeto po: Grimsey, M.K. Lewis, Public Private Partnerships, str. 96-99).

Primeri storitev, ki jih lahko zagotavlja zasebni sektor $v$ bolnišnicah $z$ zasebnim financiranjem (PFI), so npr.: vzdrževanje okolja bolnišnice, vzdrževanje stavb in opreme, catering, pranje, odpadki, dezinfekcija, varnostna služba in recepcija, nenujni prevozi pacientov, informacijski sistemi, finančne storitve, parkiranje, telekomunikacije, ogrevalni sistemi, storitve sterilizacije, ponudba trgovskih in gostinskih storitev, poštne storitve, hotelska namestitev, dnevna oskrba (Felicetti, Cecilia, 2003: Focus on advisory activity of Finlomarda on PF:PPP: experiences in Healthcare sector, dostopno na http: www.hellaskps.gr/7eppa/files/Finlombarda.ppt). 
Elda Gregorič Rogelj

\section{Javno zasebno partnerstvo $v$ zdravstvu}

Tabela 1: Oblike sodelovanja zasebnega sektorja v bolnišnicah s prikazom odgovornosti javnega in zasebnega partnerja

\begin{tabular}{|c|c|c|}
\hline Možnosti & $\begin{array}{c}\text { Odgovornost } \\
\text { zasebnega partnerja }\end{array}$ & $\begin{array}{l}\text { Odgovornost javnega } \\
\text { partnerja }\end{array}$ \\
\hline $\begin{array}{l}\text { Oddajanje nekliničnih } \\
\text { podpornih storitev zunanjim } \\
\text { izvajalcem (outsourcing) }\end{array}$ & $\begin{array}{l}\text { Zagotavlja neklinične storitve } \\
\text { (čiščenje, oskrba, pranje, } \\
\text { varnost, investic.vzdrževanje). }\end{array}$ & $\begin{array}{l}\text { Zagotavlja vse klinične } \\
\text { storitve (vključno z osebjem) in } \\
\text { bolnišnično upravljanje. }\end{array}$ \\
\hline $\begin{array}{l}\text { Oddajanje kliničnih podpornih } \\
\text { storitev zunanjim izvajalcem } \\
\text { (outsourcing) }\end{array}$ & $\begin{array}{l}\text { Zagotavlja klinične podporne } \\
\text { storitve kot npr. radiologija in } \\
\text { laboratorijske storitve. }\end{array}$ & $\begin{array}{l}\text { Upravljanje bolnišnice in } \\
\text { zagotavljanje kliničnih storitev. }\end{array}$ \\
\hline $\begin{array}{l}\text { Oddajanje specializiranih } \\
\text { kliničnih storitev zunanjim } \\
\text { izvajalcem } \\
\text { (outsourcing) }\end{array}$ & $\begin{array}{l}\text { Zagotavlja specializirane klinične } \\
\text { storitve, kot npr. lithotripsija ali } \\
\text { rutinske posege (odstranitev } \\
\text { katarakte). }\end{array}$ & $\begin{array}{l}\text { Upravljanje bolnišnice in } \\
\text { zagotavljanje izvajanje kliničnih } \\
\text { storitev. }\end{array}$ \\
\hline $\begin{array}{l}\text { Umestitev zasebnega dela } \\
\text { bolnišnice znotraj le-te ali } \\
\text { ob javni bolnišnici }\end{array}$ & $\begin{array}{l}\text { Izvajanje zasebnega } \\
\text { bolnišničnega programa (za } \\
\text { zasebne paciente), lahko } \\
\text { zagotavlja le storitev } \\
\text { namestitve ali tudi klinične } \\
\text { storitve. }\end{array}$ & $\begin{array}{l}\text { Upravljanje javne bolnišnice } \\
\text { za javni del in pogodbeno } \\
\text { razmerje z zasebnim delom } \\
\text { zaradi delitve stroškov, osebja } \\
\text { in opreme. }\end{array}$ \\
\hline $\begin{array}{l}\text { Najem in upravljanje javne } \\
\text { bolnišnice }\end{array}$ & $\begin{array}{l}\text { Upravljanje javne bolnišnice v } \\
\text { skladu s pogodbo z vlado ali } \\
\text { zavarovalnico ter zagotavljanje } \\
\text { kliničnih, oz. nekliničnih storitev. } \\
\text { Lahko zaposluje celotno osebje } \\
\text { bolnišnice in je odgovoren za } \\
\text { vlaganja, v skladu s pogodbo. }\end{array}$ & $\begin{array}{l}\text { Pogodbeno urejanje javnih } \\
\text { bolnišničnih storitev z } \\
\text { zasebnim partnerjem, plačilo } \\
\text { zasebnemu upravljalcu za } \\
\text { opravljene storitve, nadzor } \\
\text { izvajanja in usmerjanje } \\
\text { izvajanja programa. }\end{array}$ \\
\hline $\begin{array}{l}\text { Zasebna izgradnja, } \\
\text { financiranje } \\
\text { in oddaja } \vee \text { najem } \\
\text { javne bolnišnice }\end{array}$ & $\begin{array}{l}\text { Izgradnja, financiranje in } \\
\text { razpolaganje z novo javno } \\
\text { bolnišnico ter oddaja v najem } \\
\text { s postopnim odkupom državi. }\end{array}$ & $\begin{array}{l}\text { Upravlja bolnišnico in } \\
\text { oblikuje načrt postopnega } \\
\text { odkupa. }\end{array}$ \\
\hline $\begin{array}{l}\text { Zasebna izgradnja, } \\
\text { financiranje in upravljanje } \\
\text { nove javne bolnišnice }\end{array}$ & $\begin{array}{l}\text { Izgradnja, financiranje in } \\
\text { upravljanje nove javne } \\
\text { bolnišnice ter zagotavljanje } \\
\text { nekliničnih ali kliničnih } \\
\text { storitev, lahko oboje. }\end{array}$ & $\begin{array}{l}\text { Zagotavlja letno nadomestilo } \\
\text { za stroške kapitala in za } \\
\text { stroške tekočega izvajanja } \\
\text { storitev. }\end{array}$ \\
\hline Prodaja javne bolnišnice & $\begin{array}{l}\text { Vzdrževanje kapacitet in } \\
\text { nadaljevanje z dejavnostjo } \\
\text { bolnišnice v skladu s pogodbo. }\end{array}$ & $\begin{array}{l}\text { Skrbi za plačilo izvajalcu za } \\
\text { klinične storitve, usmerja in } \\
\text { nadzira v skladu s pogodbo. }\end{array}$ \\
\hline
\end{tabular}

Vir: Prirejeno po Taylor and Blair, 2002 v Darrin Grimsey and Mervyn K. Lewis, Private Public Partnerships, str. 97 
Elda Gregorič Rogelj

Javno zasebno partnerstvo v zdravstvu

Odločitev države o obliki sodelovanja je odvisna od bolnišničnih potreb po storitvah in sposobnosti države usmerjati in učinkovito nadzorovati kakovost zdravstvenih storitev. Zelo pomembno je javno mnenje o potrebnosti reformnih sprememb in vlogi države pri zagotavljanju zdravstvenega varstva. Najpogostejši modeli javno zasebnega partnerstva $\vee$ bolnišnicah so prikazani $\vee$ Tabeli 2.

\section{Tabela 2: Modeli javno zasebnega partnerstva v bolnišnicah}

\begin{tabular}{|c|c|}
\hline Model & Opis \\
\hline Franšizing & Javni partner s pogodbo prenese upravljanje bolnišnice. \\
\hline $\begin{array}{l}\text { D B F O (projektiranje, gradnja, } \\
\text { financiranje, } \\
\text { delovanje) }\end{array}$ & $\begin{array}{l}\text { Zasebni partner planira in zgradi objekt, financira in upravlja } \\
\text { bolnišnico. }\end{array}$ \\
\hline $\begin{array}{l}\text { B O O (izgradnja, lastništvo, } \\
\text { izvajanje) }\end{array}$ & $\begin{array}{l}\text { Javni partner s pogodbo odda izgradnjo lastništvo in vodenje } \\
\text { bolnišnice. }\end{array}$ \\
\hline $\begin{array}{l}\text { B O O T (izgradnja, lastništvo, } \\
\text { izvajanje, prenos) }\end{array}$ & $\begin{array}{l}\text { Javni partner s pogodbo dogovori za določeno obdobje, poleg } \\
\text { izgradnje objekta tudi izvajanje zdr. storitev, zasebni partner } \\
\text { prenese lastništvo na javnega partnerja. }\end{array}$ \\
\hline $\begin{array}{l}\text { B O L B (nakup, lastništvo, } \\
\text { lizing, prenos) }\end{array}$ & $\begin{array}{l}\text { Zasebni izvajalec zgradi bolnišnico, ima } v \text { lastni objekt, prenese } \\
\vee \text { lizing ter po določenem obdobju prenese objekt } \vee \text { last } \\
\text { javnemu partnerju. }\end{array}$ \\
\hline$A L Z \mid R A$ & $\begin{array}{l}\text { Zasebni izvajalec zgradi in upravlja bolnišnico ter s pogodbo } \\
\text { dogovori izvajanje zdravstvenih storitev. }\end{array}$ \\
\hline
\end{tabular}

Vir: Povzeto po: McKee, Nigel Edvards, Rifat Atun 2006, Bulletin of the WHO

Upoštevaje izkušnje z JZP $v$ državah z mešanim javno zasebnim načinom izvajanja zdravstvenega varstva, kot so Avstralija, Španija in Velika Britanija, so nekatere oblike JZP značilne za gradnjo in delovanje bolnišnic z modelom, v sklopu katerega javni partner odda projektiranje, izgradnjo in vodenje bolnišnice. Pregled izkušenj je omejen in strogega vrednotenja tovrstnih modelov primanjkuje. Pomembna so štiri vprašanja: stroški, kakovost, kompleksnost ter fleksibilnost. Novi objekti, zgrajeni $\vee$ JZP, so bili po dosegljivih izkušnjah $v$ državah $z$ daljšo tradicijo izvajanja $\vee$ JZP dražji v primerjavi z izvedbo 
Elda Gregorič Rogelj

Javno zasebno partnerstvo v zdravstvu

na tradicionalen način. Izgradnjo objektov $\vee$ sicer planiranem času ter upoštevaje razpoložjiva finančna sredstva $v$ ta namen, kar je mogoče šteti kot prednost izvedbe projektov $\vee$ JZP, spremlja dejstvo, da gre to tudi na račun kakovosti izgradnje (povzeto po: M.McKee,Nigel Edvards, Rifat Atun, Bulletin of the World Health Organization 2006;84:890-896).

Proučitev situacij, kjer je javni sektor izvajal projekte $v$ javno zasebnem partnerstvu z zasebnim sektorjem za vodenje in $v$ določenih primerih izgradnjo bolnišnic, izkazuje, da se pričakovanja javnega sektorja glede privatnega financiranja zdravstvenih projektov niso $v$ celoti izpolnila. Nove zmogljivosti so bile, upoštevaje celovite stroške in gledano $v$ daljšem časovnem obdobju, $v$ splošnem dražje, zlasti upoštevaje kasnejše stroške za odpravo napak pri izgradnji.

Da bi zmanjšali tveganje javnega partnerja, tako da bi del tveganja prevzel zasebni partner, kar bi izboljšalo pogoje za sklenitev JZP, je po izkušnjah težko izpolniti, zlasti zaradi zahtevnosti zdravstvenih projektov in hitro se spreminjajočih razmer (Martin McKee, Nigel Edvards, Rifat Atun, WHO 2006).

\section{JZP v mešanem javno zasebnem zdravstu v Sloveniji}

$\checkmark$ mešanem javno zasebnem zdravstvu $\vee$ Sloveniji imamo med različnimi možnimi oblikami JZP $\vee$ pretežni meri razvit le zasebni način izvajanja zdravstvenih programov $s$ koncesijami in oddajanje izvajanja storitev zunanjim, zasebnim izvajalcem (outsourcing) zaradi konkurenčnejšega izvajanja zlasti podpornih, nemedicinskih storitev.

Po obsežni zdravstveni reformi zdravstva $\vee$ Sloveniji v letu 1992, ko smo spremenili povsem državni $\vee$ mešani javno zasebni način zagotavljanja sredstev za zdravstveno varstvo ter omogočili tudi zasebni način izvajanja zdravstvenih storitev, v zdravstvu ni prišlo do temeljitejših sistemskih sprememb. V Sloveniji so do leta 1992 izvajali zdravstveno dejavnost javni zdravstveni zavodi. S podeljevanjem koncesij je bilo omogočeno zasebno izvajanje zdravstvenih storitev $\checkmark$ javni zdravstveni službi. Obseg zasebnega načina izvajanja zdravstvenih storitev $\mathrm{s}$ podeljevanjem koncesij se je $\mathrm{v}$ tem obdobju povečeval $\mathrm{z}$ naraščajočim trendom, kar nazorno prikazujejo podatki Zavoda za zdravstveno 
Elda Gregorič Rogelj

Javno zasebno partnerstvo $v$ zdravstvu

zavarovanje Slovenije (v nadaljevanju ZZZS) na Sliki 1, ki pa upoštevajo število nosilcev sklenjenih pogodb. Prikaz števila le-teh je treba obravnavati v povezavi s podatki o obsegu in vrednostjo programa zdravstvenih storitev, za katerega sklepajo javni zavodi in zasebni izvajalci pogodbe z ZZZS in izkazuje 13,8 odstotno udeležbo zasebnih izvajalcev $\vee$ finančnih sredstvih za zdravstvene storitve. V letu 2008 je ZZZS sklenil pogodbe skupno s 1767 izvajalci, od tega z 221 javnimi zavodi in s 1546 zasebnimi izvajalci s koncesijo.

\section{Slika 1: število sklenjenih pogodb ZZZS z zdravstvenimi zavodi med letoma 1993 - 2008}

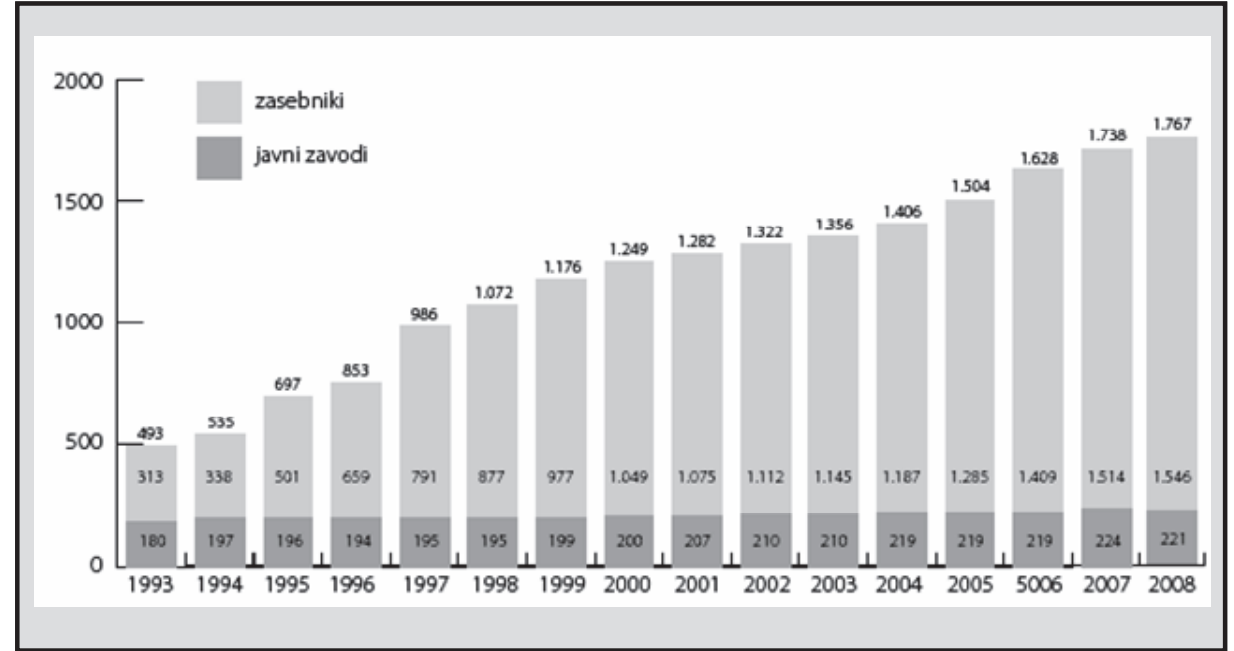

Vir: Poslovno poročilo ZZZS za leto 2008, april 2009

V celotnem obdobju, od spremembe zdravstvene zakonodaje, se je število zasebnih izvajalcev povečevalo najhitreje med leti 1994 in 2000 ter ponovno po letu 2004. Na primarni ravni je trenutno ena tretjina koncesionarjev, večina je organiziranih $v$ samostojne prakse, ki so del sistema javnega zdravstvenega varstva (Poslovno poročilo ZZZS za leto 2008, ZZZS, Ljubljana, april 2009).

Po letu 2000 imamo v Sloveniji na področju zdravstva poleg koncesij in oddaje nekaterih storitev zasebnim zunanjim izvajalcem tudi posamične primere drugih oblik JZP, ki so podrobneje obravnavani v petem poglavju prispevka. Gre za izvedbo projektov $\vee$ OZ Gorenjske, kjer lahko govorimo o modelu BOO v kombinaciji s koncesijo izvajanja storitev, načrtovanega projekta novega vhoda na IRI Ljubljana, kjer lahko govorimo o poslovnem modelu BOT, projektu pogodbenega zagotavljanja prihrankov energije, ki ga lahko označimo kot model 
Elda Gregorič Rogelj

Javno zasebno partnerstvo v zdravstvu

DFBO. Pri primeru izgradnje dializnega centra $\vee$ Bolnišnici Sežana ni mogoče govoriti o pravi obliki JZP, temveč o pogodbenem investitorjevem financiranju.

Kljub veljavnosti Zakona o JZP od marca 2007 v zdravstvu v Sloveniji ne zasledimo projektov za večja vlaganja $\vee$ opremo ali objekte, ki bi bili načrtovani $\checkmark$ partnerstvu z zasebnim sektorjem, kar potrjujejo podatki Poročila o sklenjenih oblikah javno-zasebnega partnerstva $\vee$ Republiki Sloveniji $\vee$ letu 2008, ki ga je pripravilo Ministrstvo za finance. Vsa navedena dejstva navajajo na sklepanje, da je poleg normativnega okvira treba vzpostaviti spodbudno okolje, $v$ katerem bodo vodstva zdravstvenih zavodov motivirana za iskanje najboljših možnosti za izvedbo načrtovanih projektov. $V$ ta namen bi morali zdravstveni zavodi pridobiti ustrezno raven samostojnosti in odgovornost za ravnanje s premoženjem, s tem pa možnost avtonomnejšega sprejemanja poslovnih odločitev. Pomembno mesto ima strategija razvoja področja, v kateri je jasno izražen interes za javno zasebno sodelovanje in splošen okvir, ki nakazuje področja in posamezne programe, ki bodo imeli prednost v prihodnjem razvoju zdravstva, kot so na primer programi podaljšanega bolnišničnega zdravljenja ob zmanjševanju bolnišničnih zmogljivosti, programi za zdravstveno nego kroničnih bolnikov, programi diagnostičnih storitev.

\section{Razpoložljivi viri javnofinančnih sredstev za vlaganja v zdravstvu}

Izvajanje projektov načrtovanja in izgradnje $v$ javno zasebnem sodelovanju je $\vee$ veliki meri odvisno od finančnih virov in pogojev za pridobitev le-teh. $V$ Sloveniji je država pristojna za zagotavljanje prostorskih in opremskih zmogljivosti $\vee$ zdravstvu kot enega ključnih pogojev za kvalitetne zdravstvene storitve in stroškovno učinkovito zdravstveno varstvo. V skladu z veljavno zdravstveno zakonodajo in Zakonom o investicijah $v$ javne zdravstvene zavode za obdobje 2008-2011 izvaja država to pristojnost z investicijskimi vlaganji v javne zdravstvene zavode na sekundarni in terciarni ravni.

Pri investicijskih vlaganjih $\vee$ zdravstvu je poleg zagotavljanja finančnih sredstev pomembno vzpostaviti pogoje investiranja, da bodo investicijska vlaganja ustrezala zdravstvenim potrebam prebivalstva in da bodo investicije izvedene učinkovito. Čeprav je npr. izgradnja nove bolnišnice finančno zahtevna, je pri odločanju o investiciji še toliko bolj pomembno upoštevati, da 
bo izvajanje zdravstvenih programov $\vee$ novozgrajeni bolnišnici zahtevalo finančna sredstva za delovanje $\vee$ prihodnosti. Ustrezne investicijske odločitve pripomorejo k izvajanju strukturnih sprememb na področju zdravstva, kot so npr. preusmeritve pri načinu izvajanja zdravstvenih programov, povečanje dnevnih obravnav, skrajševanje ležalne dobe, druge oblike izvenbolnišničnega zdravljenja (povzeto po Martin McKee, Judith Healy, Investing in Hospitals).

$Z$ investicijami $v$ zdravstveno mrežo se oblikujejo pogoji za delovanje, spremembe in razvoj zdravstvenih dejavnosti ter programov na državni ravni. $V$ Sloveniji smo glede na stanje zdravstvene mreže, ki je na tem mestu obravnavana kot materialni, prostorski in drugi viri, v letu 1994 sprejeli Zakon o investicijah $\vee$ javne zdravstvene zavode, na podlagi katerega so z letnimi programi določeni investicijski projekti za izgradnjo prioritetnih zmogljivosti $v$ zdravstveni mreži.

Višina in gibanje proračunskih sredstev za investicije $v$ zdravstvene zavode v letih 2002-2007 sta prikazani v Tabeli 3. Podatki o realiziranih investicijskih vlaganjih $\vee$ zdravstveno mrežo za obdobje 2002-2008 izkazujejo zmerno povečanje obsega vlaganj, vendar višina $v$ odnosu na načrtovana vlaganja ne zagotavlja uspešnega zaključevanja planiranih investicijskih vlaganj.

Finančni viri za investicijska vlaganja $v$ zdravstvu so poleg proračunskih sredstev, sredstva združene amortizacije, lastni finančni viri zdravstvenih zavodov ter sredstva od odprodaje državnega premoženja, ki se združujejo $v$ proračunskem skladu' ${ }^{\mathbf{1}}$ za investicije $v$ javne zdravstvene zavode.

Amortizacija je sicer namenjena obnavljanju in izboljšanju osnovnih in drugih sredstev (neopredmetenih dolgoročnih sredstev, nepremičnin, opreme), katerih vrednost se zmanjšuje z odpisanostjo, zato ta vir $v$ zdravstvenih zavodih niti po namenu, kot tudi glede na višino, ne zadošča za večja investicijska vlaganja. Delež obračunane amortizacije $v$ celotnem prihodku bolnišnic je v letu 2008 znašal 4,23 \% (Vir: Poročilo o doseženih poslovnih rezultatih JZZ in lekarn $\checkmark$ letu 2008, Ministrstvo za zdravje, junij 2009). Amortizacijska sredstva zdravstveni zavodi $\vee$ pretežni meri namenjajo za najnujneša investicijska

1 Proračunski sklad je podračun, ustanovljen na podlagi Zakona o investicijah v javne zdravstvene zavode, katerih ustanovitelj je RS, za obdobje 2008-2011. Viri financiranja sklada so: -namenski prihodki proračuna, ki se preko pravic uporabe namenske postavke sredstev amortizacije in drugih virov po ZIJZ izločajo na podračun proračunskega sklada, in integralni prihodki proračuna, ki se preko postavke "investicije $v$ javne zdravstvene zavode« izločijo na podračun proračunskega sklada

- del amortizacije javnih zdravstvenih zavodov

- darila, volila in druga namenska sredstva

- prejemki od sredstev, ki jih osebe zasebnega prava namenijo za investicije v opremo in objekte javnih zdravstvenih zavodov. 
Elda Gregorič Rogelj

Javno zasebno partnerstvo $v$ zdravstvu

vlaganja za nadomeščanje opreme, investicijsko vzdrževanje, obnavljanje in izboljšave obstoječih prostorskih zmogljivosti, medtem ko za večja investicijska vlaganja za nadomestitev zahtevnejše medicinske in druge opreme ter za vlaganja $\vee$ nove prostorske zmogljivosti obstoječi finančni viri ne zadoščajo. $V$ povezavi s tem je visoka stopnja odpisanosti osnovnih sredstev zdravstvenih zavodov, ki izkazuje za leto 2008 78,03 \% iztrošenost opreme in 53,7 \% iztrošenost vseh osnovnih sredstev in je posledica prepočasnega nadomeščanja in obnove zaradi pomanjkanja finančnih virov (Podatki in kazalci poslovanja zdravstvenih zavodov Slovenije za leto 2008, ZZZS).

Tabela 3: Višina in gibanje proračunskih sredstev za investicije v zdravstvene zavode v letih 2002-2008, v 000 EUR

\begin{tabular}{|c|c|c|c|c|c|c|c|}
\hline & 2002 & 2003 & 2004 & 2005 & 2006 & 2007 & 2008 \\
\hline $\begin{array}{l}\text { Investicijska vlaganja } \\
\text { v bolnišnice }\end{array}$ & $25.872,29$ & $40.503,99$ & $37.569,57$ & $27.132,32$ & $41.406,10$ & $46.396,75$ & $51.825,78$ \\
\hline $\begin{array}{l}\text { Investicijska } \\
\text { vlaganja v bolnišnice } \\
\text { - proračun }\end{array}$ & $14.420,88$ & $28.709,56$ & $30.590,93$ & $20.868,29$ & $34.565,58$ & $42.532,69$ & $45.681,05$ \\
\hline $\begin{array}{l}\text { Sredstva } \\
\text { amortizacije } \\
\text { in drugi viri }\end{array}$ & $6.430,29$ & $11.484,08$ & $6.978,64$ & $6.261,82$ & $6.840,52$ & $3.826,26$ & $6.143,08$ \\
\hline $\begin{array}{l}\text { Izgradnja } \\
\text { Pediatrične klinike }\end{array}$ & $5.021,12$ & 0 & 0 & 0 & 0 & 0 & 0 \\
\hline $\begin{array}{l}\text { Investicije - } \\
\text { Prodaja in menjava } \\
\text { premoženja JZZ }\end{array}$ & 0 & 0 & 0 & 2,21 & 0 & 37,80 & 1,65 \\
\hline $\begin{array}{l}\text { Sofinanciranje } \\
\text { investicij v osn. ZV }\end{array}$ & 0 & 0 & 822,79 & $1.851,12$ & $1.952,45$ & $1.586,06$ & $1.431,02$ \\
\hline Skupaj & $25.872,29$ & $40.503,99$ & $38.392,36$ & $28.983,44$ & $43.358,55$ & $47.982,81$ & $53.256,80$ \\
\hline
\end{tabular}

Vir podatkov: Podatki MF, Direktorat za proračun, Podatki za leto 2007 in 2008 - MFERAC 
Elda Gregorič Rogelj

Javno zasebno partnerstvo $v$ zdravstvu

$\checkmark$ Sloveniji znaša delež javnofinančnih sredstev za infrastrukturne naložbe le 5,1 \% javnofinančnih sredstev za zdravstvo (Slika 2). Zaradi javnofinančnih pritiskov bodo čedalje večje potrebe po alternativnih virih financiranja, zlasti za investicijska vlaganja $\vee$ zdravstvene zmogljivosti, med katerimi so posebej finančno zahtevne naložbe $v$ zdravstveno opremo in objekte. Tudi spremembe $v$ načinu izvajanja zdravstvenih programov in $v$ potrebah uporabnikov bodo imele za posledico spremembo namembnosti zdravstvenih objektov ali gradnjo novih, kar bo zahtevalo večja finančna sredstva za investicije $v$ zdravstvu, ki jih bo potrebno zagotavljati tudi iz nejavnih virov.

Javnofinančni okviri za financiranje zdravstvenega varstva ne omogočajo zadostnih sredstev za investicijska vlaganja. Za investicijska vlaganja $\vee$ obnovo, izboljšanje ali nadomeščanje obstoječih nepremičnin $\vee$ zdravstvenih zavodih, obstoječi finančni viri zdravstvenih zavodov in proračunski viri, določeni z letnimi finančnimi načrti ne zadoščajo. Tudi projekcije javnofinančnih odhodkov za zdravstveno varstvo za obdobje 2008-2013 predvidevajo nadaljnje postopno znižanje deleža javnofinančnih odhodkov $\vee$ obveznem zdravstvenem zavarovanju.

Slika 2: Izdatki za zdravstvo po vrstah obravnav in virih financiranja 2003-2008

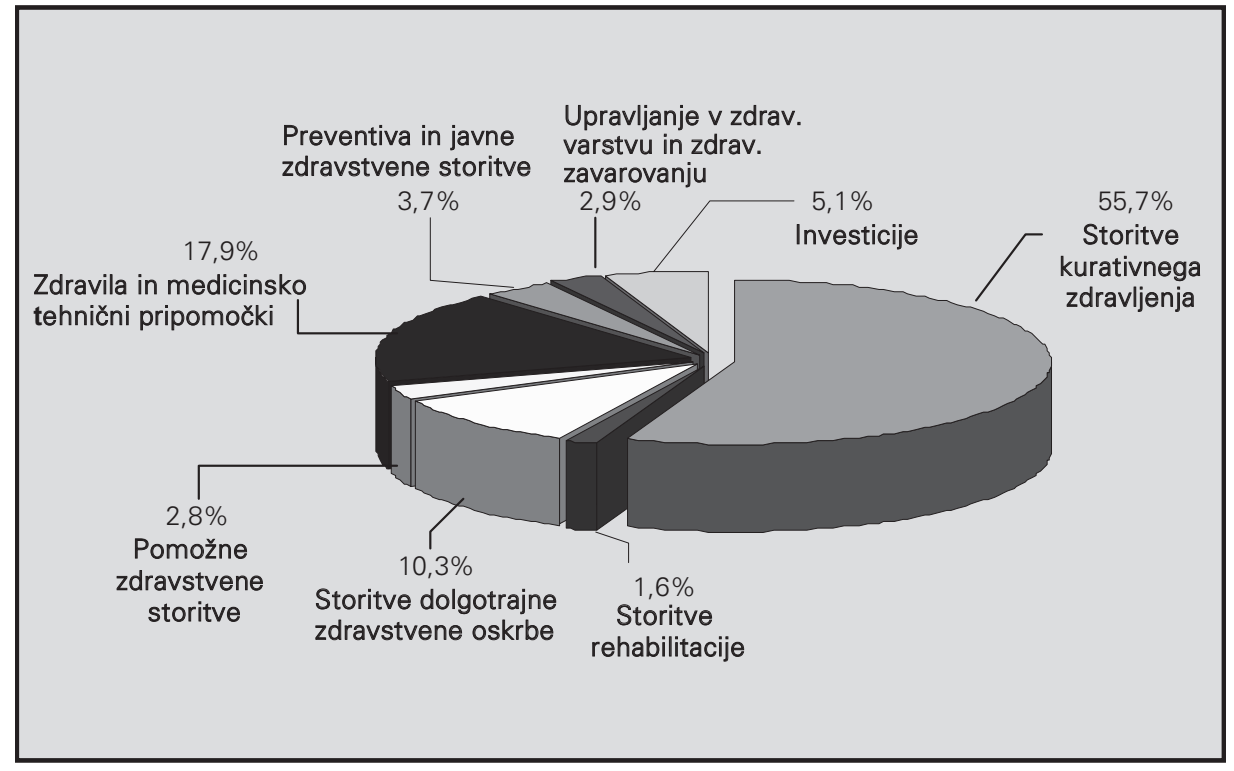

Vir: Podatki Statističnega urada Republike Slovenije 
Elda Gregorič Rogelj

Javno zasebno partnerstvo v zdravstvu

\section{Prikaz nekaterih Projektov JZP v zdravstvu v Sloveniji}

Tako kot $v$ drugih okoljih je tudi $v$ Sloveniji glavni motiv javnega sektorja za projekte JZP zagotovitev sredstev za vlaganja in zagotavljanje kakovostnejših storitev uporabnikom $\vee$ okviru omejenih javnih sredstev. Ker vseh potrebnih investicijskih vlaganj $v$ zdravstveno mrežo $s$ proračunskimi viri ni mogoče zagotoviti, so se nekateri zdravstveni zavodi že $\vee$ obdobju pred veljavnostjo ZJZP odločali za pridobitev zasebnih sredstev za izvedbo načrtovanih investicij. Prvi primeri izvedbe projektov skupnih vlaganj $\vee$ JZP so bili izvedeni že pred desetimi leti, kot je primer treh objektov Osnovnega zdravstva Gorenjske, zgrajen in financiran $v$ sistemu JZP na osnovi dokaj dobrega skupnega sodelovanja in cilja treh partnerjev, in sicer občin, države (ministrstva), javnih zdravstvenih zavodov in zasebnih vlagateljev. Bolnišnica Sežana je v letih 2004-2005 izvedla izgradnjo dializnega centra $v$ obliki javno-zasebnega sodelovanja z investitorjem. Splošna bolnišnica Brežice je leta 2006 sklenila pogodbeno partnerstvo za zagotavljanje prihranka energije in dobave energentov ter rekonstrukcijo kotlarne. Inštitut za rehabilitacijo invalidov RS je v letu 2007 pripravil projekt novega vhoda in spremljajočih prostorov na IRI po modelu BOT, preveril interes zasebnih vlagateljev, vendar do realizacije projekta še ni prišlo.

$\checkmark$ teku ali v pripravi so tudi zasebna vlaganja za izgradnjo parkirišč ob nekaterih bolnišnicah.

\subsection{Osnovno zdravstvo Gorenjske (OZG)}

JZP v primeru OZG predstavlja skupno javno zasebno investiranje gorenjskih občin, zasebnih vlagateljev in javnega zavoda s ciljem zagotovitve poslovnih prostorov na skupni lokaciji zaradi ohranitve zdravstvenega doma kot načina izvajanja zdravstvenih storitev na primarni ravni v mešanem javno zasebnem zdravstvu.

Izgradnja skupnih zdravstvenih objektov (Škofja Loka, Radovljica, Tržič) v obliki financiranja JZP, se je izkazala kot pravilna $\vee$ pogojih mešanega javno zasebnega zdravstva na primarni ravni na območju gorenjskih občin. Vse tri investicije so bile finančno precej zahteven projekt, saj je bila vrednost objekta $\vee$ Škofji Loki 1,1 mio EUR, v Radovljici 450.000 EUR in $\vee$ Kranju 5 mio EUR. Zasebna sredstva so skupno s proračunskimi (občinskimi in delno sredstva 
Elda Gregorič Rogelj

Javno zasebno partnerstvo v zdravstvu

Ministrstva za zdravje) omogočila realizacijo investicije, pri čemer je bil uveden boljši nadzor izvedbe investicije. Z izgradnjo novih prostorov za izvajanje zdravstvene dejavnosti na primarni ravni je bila omogočena koncentracija vseh zmogljivosti na eni lokaciji, s tem pa tudi razpoložljivost zdravstvenih dejavnosti za paciente na skupni lokaciji. K uspešni realizaciji projekta je $\vee$ veliki meri prispeval premoženjski sporazum med 18 gorenjskimi občinami in OZG, ki zavezuje občine za ureditev lastništva $\vee$ zemljiški knjigi in za oddajo $\vee$ upravljanje OZG. Sredstva v upravljanju - vrednost premičnin in nepremičnin ter najemnina so prenesena $\vee$ upravljanje OZG, kar predstavlja pomembno spodbudo za javni zavod, saj lahko prihodek iz tega naslova namenja za vlaganja $v$ objekt in za nagrajevanje zaposlenih (povzeto po Veternik J., Javno zasebne investicije pri izgradnji prostorov Osnovnega zdravstva Gorenjske, 14. strokovno srečanje ekonomistov in poslovodnih delavcev v zdravstvu, Radenci 2007).

Javno zasebno sodelovanje je bilo vzpostavljeno pri zagotovitvi zainteresiranih vlagateljev, pri pogodbenem urejanju financiranja gradnje, uporabi in vzdrževanju zgrajenih objektov, prav tako pa tudi pri izvajanju dejavnosti, kjer zasebni vlagatelji nastopajo kot etažni lastniki poslovnih prostorov in so bodisi zasebniki - koncesionarji ali zasebna podjetja, ki izvajajo z zdravstvom povezano dejavnost. $V$ pogledu modela JZP lahko govorimo o modelu BOO (built own operate) $\vee$ kombinaciji s koncesijo izvajanja storitev. Za model je značilno, da ostajata javni in zasebni partner trajneje povezana. Ob izteku koncesije običajno javni partner prevzame odgovornost za uporabo in upravljanje objekta z namenom ohranitve izvajanja koncesijske dejavnosti. Ker gre za uporabo oblike JZP na področju primarnega zdravstvenega varstva, ki izkazuje tudi druge pozitivne učinke povezanega delovanja javnih in zasebnih izvajalcev, je ta primer JZP $\vee$ našem okolju vreden pozornosti.

\subsection{Izgradnja novega vhoda in spremljajočih prostorov na Inštitutu $R S$ za rehabilitacijo invalidov (IRI)}

IRI je ocenil, da sta projekt izgradnje spremljajočih prostorov za izvajanje podpornih dejavnosti za uporabnike in njegova funkcija primerna za iskanje investicijskih virov $v$ JZP. Lastni finančni viri IRI niso omogočali izvedbe tovrstne investicije, plan investicijskih vlaganj $\vee$ javne zdravstvene zavode $s$ proračunskimi sredstvi pa te investicije ne predvideva. Projekt $\vee$ vrednosti 4,7 mio EUR je namenjen celostni ponudbi storitev za obiskovalce, paciente in 
Elda Gregorič Rogelj

Javno zasebno partnerstvo v zdravstvu

invalide. Zasebni vlagatelj bi zgradil objekte ter zagotovil opremo, koncedentov vložek bi bilo zemljišče in priprava dokumentacije JZP.

Glede na več možnih načinov upravljanja vložka je inštitut za projekt novega vhoda kot najprimernejšega izbral sistem, ko objekti in naprave postanejo last javnega partnerja po določenem času (BOT), saj se $s$ tem prenese celotna investicija, upravljanje in vzdrževanje objekta na zasebnega partnerja. Odločitev je smiselna, glede na to da bi bilo $v$ tem primeru sklenjeno koncesijsko JZP, katerega predmet bi bila koncesija gradnje in bi zasebni partner lahko zagotovil povrnitev vloženih sredstev iz naslova prihodkov za oddajo prostorov, $\checkmark$ katerih bi potekalo izvajanje storitev, pri čemer je treba upoštevati maksimalni rok za podelitev koncesije. Izračun upravičenosti investicije je pokazal, da bi se investicija začela vračati po preteku 24 let. IRI bi ob primerno opredeljeni pogodbi za izvedbo projekta $\mathrm{z}$ zasebnim partnerjem $\vee$ javno zasebnem sodelovanju zagotovil celostno in funkcionalno zaključeno podobo inštituta, možnost uporabe prostorov $v$ novem vhodu in avle, ki bi bila namenjena pacientom in obiskovalcem ter bi zagotavljala širšo in kvalitetnejšo ponudbo storitev. Tveganje je $\vee$ primeru pripravljenega projekta $\vee$ prvi vrsti na strani zasebnega vlagatelja, ob predpostavki, da bo moral zgrajene prostore oddajati, kar pa mu bo lahko zagotavljalo pričakovani donos, če se bodo $v$ novih prostorih uspešno izvajale predvidene dopolnilne in podporne dejavnosti. Inštitut bo $v$ primeru odločitve za JZP sklenil koncesijsko JZP s predmetom koncesija gradnje. Na strani javnega partnerja je po zakonu RS, lahko pa bi Vlada RS to vlogo prenesla na IRI (povzeto: Cugelj R., Možnost JZP pri izgradnji novega vhoda in spremljajočih prostorov na IRI, 14. strokovno srečanje ekonomistov in poslovodnih delavcev v zdravstvu, Radenci 2007).

Za izvedbo projekta $\vee$ JZP bi sicer lahko izbirali med oblikami JZP, kot so BTO, BOT in BOO. Za projekt JZP pri izgradnji »novega vhoda $|\mathrm{R}|$ « se bo inštitut predvidoma odločil, ko bodo zasebni vlagatelji izkazali interes.

\subsection{Splošna bolnišnica Brežice - pogodbeno partnerstvo na področju pogodbenega zagotavljanja prihranka energije in dobave energentov - rekonstrukcije kotlarne}

Vodstvo bolnišnice se je za prenovo ogrevalnega sistema $\vee$ JZP odločilo zaradi okoliščin, ko kot manjša bolnišnica nimajo veliko možnosti za pridobitev proračunskih sredstev za vse investicijske potrebe. Tudi ocena možnosti najetja kredita se je izkazala kot zahtevnejši in dolgotrajnejši postopek, zato so se 
odločili za alternativni način izvedbe investicije, in sicer z JZP. Obenem je obstajal motiv zasebnega partnerja Petrola d.d. Ljubljana za vložek $\vee$ ogrevalni sistem bolnišnice, ki se je izkazal tudi s pripravljenostjo za pripravo projektne naloge, oz. s sodelovanjem $\vee$ procesu planiranja in priprave investicije. Zasebni partner je bil pripravljen prevzeti odgovornost za ustvarjanje prihrankov pri ogrevanju in tveganje. Posebej zahteven postopek načrtovanja prihrankov in cene energentov so $\vee$ fazah pogajanj o pogodbi izvedli $\vee$ daljšem obdobju, zavedajoč se pomembnosti opredelitve vseh tveganj, skrbne ocene stroškov in koristi.

Bolnišnica je preverila ekonomsko upravičenost investicije in izračunala prihranke zaradi posodobitve naprav, toplotnih postaj in preostalih posodobitev ter prihranke zamenjave energenta. Ob upoštevanju končnega izračuna prihrankov, ki temelji na referenčni porabi ELKO in propana v letu 2005, s spremembo energenta in prehodom na zemeljski plin, sanacijo rezervoarjev ter $z$ investicijo $v$ termični del kuhinje $s$ prezračevanjem je bilo ocenjeno, da bi bolnišnica letno zmanjšala stroške ogrevanja za $26,6 \%$, kar se je s spremljanjem učinkov $v$ naslednjih letih izkazalo kot realno, oziroma so bili prihranki celo višji. Velikost bolnišnice ni omogočala poplačila investicije iz prihrankov energije. Zato Bolnišnica Brežice zagotavlja plačila iz treh delov, in sicer iz osnovnega fiksnega plačila za glavno storitev, ki se nanaša na Petrolovo jamstvo prihranka okoli $25 \%$, iz odstotka bonusa - variabilno plačilo, kot dodatna stimulacija za dosego višjih prihrankov od zagotovljenih (25\% Petrol, 75 \% SB Brežice) in iz dodatnega fiksnega plačila za zagotavljanje izvedbe celotnega projekta.

$\checkmark$ pogledu prevzema tveganja $\vee$ projektu JZP SB Brežice je na osnovi sklenjene pogodbe mogoče ugotoviti, da sta oba partnerja, tako javni - SB Brežice kot zasebni - Petrol d.d. Ljubljana tveganje opredelila odgovorno in podrobno. Predvideno je, da ima bolnišnica pravico veta za primere ravnanj ali stanj, da bi bili ukrepi za prihranke energije nezdružljivi z zakoni ali predpisi, da bi bili v nasprotju z osnovnim namenom pogodbe ali če bi se pri naročniku pojavil dvom o ukrepih za prihranek energije glede izpolnjevanja zahtev glede kakovosti ali o transparentnosti. Za primer, da ne bi bil dosežen vnaprej opredeljeni obseg investicije, lahko naročnik do konca trajanja pogodbe uveljavlja zmanjšanje $\vee$ obliki znižanja udeležbe, ki pripada izvajalcu za odstotek, sorazmeren neizvršenemu obsegu investicije. Za naročnika je glavno tveganje, da ne bi bilo doseženo zmanjšanje porabe in stroškov energije, zato je predvideno jamstvo prihranka, ki ga izvajalec garantira kot glavno storitev, in sicer na način, 
Elda Gregorič Rogelj

Javno zasebno partnerstvo v zdravstvu

da bodo za čas pogodbe prihranki zagotovljeni v vnaprej opredeljeni višini. Bolnišnica ima dogovorjeno pravico prenehanja dobave energenta, če naročnik dobi na trgu cenejši energent. Tveganje na strani bolnišnice je za primer likvidacije ali stečaja izvajalca, za kar pogodba predvidi predkupno pravico naročnika na neamortiziranem delu naprav in stvari, ki jih je vgradil izvajalec.

Zasebni partner je za preprečitev tveganj na svoji strani v pogodbi dogovoril odškodninske zahteve, če so razlogi za preprečitev izvajanja ukrepov nastali zaradi nepoznavanja ovir in jih izvajalec ni poznal. Naročnik nosi tveganje, če izvajalec ne doseže vsote investicije ali pride do odstopanj pri strukturi investicije, saj naročniku v tem primeru ne pripadajo zahteve za zmanjšanje, ker so odstopanja nastala po njegovi krivdi. Izvajalec se je ustrezno zavaroval za primer odsvojitve stavbe, pravnega nasledstva ali opustitve stavbe, saj je $v$ tem primeru $v$ pogodbi predvideno, da se $z$ odsvojitvijo ali prepustitvijo, prenesejo na novega lastnika obveznosti iz pogodbe.

Lastništvo vseh naprav in stvari, ki jih vgradi izvajalec, ostaja do polnega poplačila vseh finančnih obveznosti naročnika do izvajalca iz te pogodbe, pri izvajalcu, Petrolu d.d. Po preteku pogodbenega obdobja preidejo vse naprave in stvari, vključno z dopolnitvami $\vee$ času trajanja pogodbe, $v$ last naročnika, SB Brežice (povzeto: Zorko T., Primer javno zasebnega partnerstva na področju zagotavljanja učinkovite rabe energije $\vee$ Splošni bolnišnici Brežice, 14. strokovno srečanje ekonomistov in poslovodnih delavcev $v$ zdravstvu, Radenci 2007).

Projekt pogodbenega zagotavljanja prihrankov energije $v$ primeru SB Brežice predstavlja model pogodbenega financiranja, ki zajema tudi načrtovanje in vgradnjo novih naprav, vodenje in nadzor obratovanja, servisiranje in vzdrževanje, odpravo motenj ter motiviranje porabnikov energije. Z vidika poslovnega modela JZP gre za skupno načrtovanje, izgradnjo, obratovanje in financiranje za določen čas ter koncesijo $v$ smislu vnaprejšnjega pogodbenega zagotavljanja energenta (DFBO). Glavno gonilo je izraba zasebnega kapitala ter prenos tveganj zasnovanja, izgradnje in obratovanja na zasebni sektor. Prednosti so povezane z motiviranostjo zasebnega sektorja za vložke, kar omogoča večji potencial za pospešeno gradnjo, večji prenos tveganj pa pomeni večjo motivacijo za t. i. whole-life costing pristop. 


\subsection{Splošna bolnišnica Sežana - izgradnja dializnega centra}

Bolnišnica Sežana glede na obseg in vsebino dogovorjenega zdravstvenega programa ni imela možnosti za pridobitev proračunskih sredstev za investicijo od Ministrstva za zdravje, prav tako tudi razpoložjivi finančni viri bolnišnice niso omogočali pričetka investicije $\vee$ izgradnjo dializnega centra. Bolnišnica je leta 2004 na podlagi elaborata o ekonomski upravičenosti investicije in določitvi velikosti dializnega centra pričela s projektom adaptacije gospodarskega dela bolnišnice $v$ vrednosti 2,5 mio EUR. Bolnišnica je poslovala $z$ izgubo $v$ tekočem poslovanju in z nepokritimi izgubami iz preteklih let, zato ni bilo možnosti za izvedbo projekta z lastnimi sredstvi. Najem kredita je bil glede na javnofinančno zakonodajo pogojen s soglasjem ustanovitelja, ki so ga ocenili kot vprašljivega. Zato je Bolnišnica Sežana pridobila investitorja, ki je bil pripravljen izvesti gradbena dela in nabaviti opremo za dializni center; investicijo je bolnišnica končala $\checkmark$ letu 2005. Postopek izbire izvajalca za gradbena dela in za dobavo opreme so izvedli z javnim naročilom. Sredstva za izvedbo projekta je bolnišnica zagotovila na način, da je pridobila donacije za izdelavo projektov ter kritje deleža stroškov za nadomestne prostore. Na največje težave so naleteli pri pridobivanju garancije. Izkazalo se je, da je za pridobivanje zasebnih vložkov $v$ javne zavode problem $\vee$ lastninskih upravičenjih in ni $\vee$ pristojnostih javnega zavoda. $\vee$ primeru Bolnišnice Sežana jim je kljub navedenim oviram uspelo doseči soglasje z investitorjem in zgraditi dializni center, za katerega odplačujejo sredstva na podlagi pogodbe z investitorjem (povzeto: Šonc S., Javno zasebna investicija pri izgradnji in opremi prostorov Dializnega centra Sežana, 14. strokovno srečanje ekonomistov in poslovodnih delavcev v zdravstvu, Radenci, 2007). Razpoložljivi podatki o pogodbenem odnosu med bolnišnico in zasebnim vlagateljem ne potrjujejo, da gre $v$ tem primeru za obliko JZP, pač pa za pogodbeno financiranje.

\section{Zaključek}

V pogojih, ko mreža javne zdravstvene službe še ni določena, so zanimivi projekti za JZP $\vee$ zdravstvenem sektorju zlasti s področja nemedicinskih in podpornih dejavnosti, kot npr. obnova ali modernizacija ogrevalnih sistemov, pranje perila, čiščenje, storitve prehrane in druge. To so potrdili tudi posamični primeri 
Elda Gregorič Rogelj

Javno zasebno partnerstvo v zdravstvu

javno zasebnih vlaganj v zdravstvu (IRI, SB Brežice), katerih vsebina so podporne in nemedicinske dejavnosti. Vlaganja zasebnega kapitala $\vee$ medicinske dejavnosti $\vee$ javno zasebnem partnerstvu so zahtevnejša in zahtevajo večjo stopnjo regulacije sistema zdravstvenega varstva $v$ smislu določitve in sprejema standardov, normativov, mreže in vzpostavljene usmerjevalne ter nadzorne vloge države.

Za izvedbo projektov $v$ javno zasebnem partnerstvu so se odločali predvsem $v$ tistih zdravstvenih zavodih, ki so bili zaradi pogojev poslovanja in nujnosti iskanja zasebnih finančnih virov pri izvedbi projektov za nadaljevanje razvoja zavoda $v$ večji meri motivirani za sklepanje partnerstva z zasebnim sektorjem. Dosedanje izkušnje zdravstvenih zavodov pri vstopanju $\vee$ JZP $\vee$ Sloveniji potrjujejo dejstvo, da javno zasebno partnerstvo ne pomeni prednostnega načina za izvajanje javne službe, oziroma za zagotavljanje finančnih virov za investicijska vlaganja, a je lahko pomemben izhod zaradi nezadostnih javnih sredstev za investicijska vlaganja, če so oblike javno zasebnega izvajanja projektov dobro načrtovane, kvalitetno upravljane ter nadzorovane. To potrjujejo tudi izkušnje drugih okolij, kjer imajo daljšo tradicijo sodelovanja javnega z zasebnim sektorjem.

Pred vstopanjem $\vee$ javno zasebna partnerstva je posebej pomembno upoštevati dejstvo, da so te oblike sodelovanja izjemno zahtevne, tako $v$ fazi načrtovanja, kot tudi $v$ fazah realizacije in upravljanja. Za javni sektor mora biti pri tem osnovno vodilo, da bo z izvedbo javno zasebnega partnerstva prednost za uporabnika večja in bo zastopan javni interes, da bo uporabljena ustrezna pravno organizacijska oblika ter bo tveganje enakomerno porazdeljeno, hkrati pa, da bodo udeleženci partnerstva dosegli zastavljene cilje.

Skupna vlaganja bi morala slediti ključnim ciljem razvoja, opredeljenimi v strategiji razvoja zdravstva. Predpostavlja pa se, da bo država dosledno izvajala usmerjevalno in nadzorno vlogo pri izvajanju projektov in vzpostavila vzvode, da bo pri javno zasebnem sodelovanju za izvajanje projektov ustrezno zavarovan javni interes.

Na področju zdravstva $\vee$ Sloveniji je za izvajanje projektov $\vee$ javno zasebnem sodelovanju poleg sprememb zakonodaje, ki bi uredila statusna in premoženjska vprašanja ter področje upravljanja, prav tako pomemben razvojni koncept področja. 
Elda Gregorič Rogelj

Javno zasebno partnerstvo v zdravstvu

Mag. Elda Gregorič Rogelj je generalna direktorica Direktorata za zdravstveno ekonomiko na Ministrstvu za zdravje. Direktorat vodi od konca leta 2008. Ima dolgoletne izkušnje na področju neprofitnega menedžmenta in zdravstvene ekonomike. V letih 1983 do 2001 je bila odgovorna za financiranje zdravstvenega varstva in za proračun v okviru Ministrstva za zdravje. Njena znanja so široka, tako s področja upravljanja $v$ zdravstvu, kot tudi s področja vodenja $v$ državni uprave.

\section{Literatura in viri}

- Buse, K., \& Walt, G. Scielo public health. (2000). Bulletin of the World Health Organization. (n.d.). Retrived 10. 4. 2008, from: http://www.scielosp.org/scielo.php?pid=S0296862000000400019\&script=sci_arttext.

- Cugelj, R. (2007). Možnost JZP pri izgradnji novega vhoda in spremljajočih prostorov na IRI. NOVIS Javno zasebno partnerstvo. 31-35.

- Gregorič-Rogelj, E. (2008). Javno zasebno partnerstvo kot možnost investiranja v javne zdravstvene zavode, mag. družboslovnih znanosti, Ljubljana, Univerza v Ljubljani, Fakulteta za družbene vede

- Grimsey, G., \& K.Lewis, M. (2007). Public Private Partnerships. Cheltenham (UK).

- Loxley, J. \& J. Loxley, A. (2007). The economic and financial aspects of public/private sector partnerships. Ekonomski vidiki javnega sektorja. Ljubljana.

- McKee, M. \& Edvards, N.\& Atun, R. (2006). Bulletin of WHO.

- McKee, M. \& Healy, J. (2002). Hospitals in a changing Europe. Buckingham, Philadelphia: Open University Press.

- Mužina, A. (2007). Zakon o JZP. GV izobraževanje.

- Mužina, A. (2005). Javno zasebno partnerstvo v teoriji. GV izobraževanje.

- Podatki in kazalci poslovanja zdravstvenih zavodov Slovenije za leto 2008. (2009). Združenje zdravstvenih zavodov Slovenije.

- Poročilo o doseženih poslovnih rezultatih JZZ in lekarn v letu 2008. (2009). Ministrstvo za zdravje RS.

- Poročilo o sklenjenih oblikah javno zasebnega partnerstva v RS v letu 2008. (2009). Ministrstvo za finance RS.

- Poslovno poročilo ZZZS za leto 2008. (2009). Zavod za zdravstveno zavarovanje Slovenije.

- Resolucija o nacionalnem planu zdravstvenega varstva 2008-2013 - Zadovoljni uporabniki in izvajalci zdravstvenih storitev (NPZV 2008-2013). (n.d). Retrived 15. 8.,2009, from http://www.mz.gov.si/fileadmin/mz.gov.si/pageuploads/aktualno/javna_razprava/javna_ra zprava_2008/nacionalni_plan_2008/Microsoft_Word_-_NPZV_javna_razprava_280108.pdf 
Elda Gregorič Rogelj

\section{Javno zasebno partnerstvo v zdravstvu}

- Setnikar-Cankar, S., et al. (2005). Ekonomika javnega sektorja in proračunsko financiranje. Fakulteta za Upravo.

- Šno, S. 2007. Javno zasebna investicija pri izgradnji in opremi prostorov Dializnega centra Sežana. NOVIS Javno zasebno partnerstvo. 39-41.

- Veternik, J. (2007). Javno zasebne investicije pri izgradnji prostorov Osnovnega zdravstva Gorenjske. NOVIS Javno zasebno partnerstvo. 67-71.

- Zakon o investicijah v javne zdravstvene zavode, katerih ustanovitelj je RS za obdobje 2008-2011.

- Zorko, T. (2007). Primer javno zasebnega partnerstva na področju zagotavljanja učinkovite rabe energije $v$ Splošni bolnišnici Brežice. NOVIS Javno zasebno partnerstvo. $51-56$. 


\section{SUMMARY}

\section{PUBLIC-PRIVATE PARTNERSHIPS IN HEALTH CARE}

The aim of Public-Private Partnerships in health care is collaboration with public and private partners in order to improve the health of population on the basis of roles and principles, defined in agreement. Collaboration must follow standards of health care and equality of access to health services. At the same time collaboration must respect partners' autonomy and prevent worsening of population health.

Because of restricted public financing resources and growing medical expenditure, there is an increasing demand for alternative financial resourcing in health care as regards investing into health care buildings, equipment and facilities.

After 1980 privatisation of health services has spread all over the world. In Western Europe countries ( Great Britain, Spain, Portugal, Germany), in the USA, Canada and Australia collaboration models in private sector partnerships with hospital private sector have developed quite intensively. Private sector collaboration models are very different - they vary from outsourcing nonclinical support services to the most extreme, like privatisation of public hospital with public partner responsibility for controlling programme realisation and assuring programme financing. There is limited experience examination and there is also a lack of rigorous evaluation models.

Four issues are exposed: cost, quality, complexity and flexibility.

Researching situations where public sector has been realising projects of private-public partnerships in collaboration with private sector for operating and in some cases hospitals building, shows us that public sector expectations, regarding private financing of health projects, have not been completely fulfilled.

Taking into account all costs and observing the process through a longer period, new facilities have been in general more expensive, especially if we consider later costs for elimination of building defects.

Nevertheless positive experience is that all so realised projects in PPP have been finished in time and in frame of agreed financial means. Parallel to this it could be established that the realisation of projects has been reached on the account of quality. The need for risk diminishing as one of 
Elda Gregorič Rogelj

Javno zasebno partnerstvo $v$ zdravstvu

the conditions for PPP on the side of public partnership and risk takeover on the side of private partner is hard to fulfil, especially in demanding conditions of health projects and in quickly modifying circumstances.

Public-private partnership in Slovenia is at the beginning phase of development, with the exception of concessions as models of PPP. In spite of validity of Law of PPP since March 2007 not many projects for larger investments in equipment or infrastructure can be traced.

In Slovenia 5.1\% public financing resources are assigned for health care capacity investments. Because of public financing pressure there will be increasing needs for finding alternative financing sources, especially for health capacity investments, among which there are very demanding investments in health equipment and buildings. Changes in the way of carrying out health programmes and services and changes in consumers' needs will consequently cause the change of intended use of health buildings or the building of new ones. All this will demand larger financial costs for investment interventions, where in the case of lack of public financial means the possibilities of private sector investments will have to be taken into account.

Current situation shows that for investments in reconstruction, improvement or replacement of existent properties in health institutions, existent financial sources of health institutions and budget sources are not sufficient. The projections of public financing expenses for health care in the period 2008 - 2013 also anticipate increasing gradual lowering of public financing expenses in public health insurance.

As all investments in health through the means of budget sources cannot be assured, some of health care centres took the decisions - already in the period before validity of PPP - to provide private investments for planned investments.

First cases of carrying out projects in collaboration investments in public health care were realised ten years ago - for example three facility buildings of primary health care in the Gorenjska region, built and financed on the basis of good collaboration and aiming of three partners communities, Ministry of Health (State), public health care institutions and private investors.

Hospital Sežana carried out building of the new Dialysis centre in the period 2004 - 2005 in the model of public-private investment. In 2006 General hospital Brežice conducted contractual partnership for providing reduced energy use and energy generating products. In 2007 Institute for 
Rehabilitation in Slovenia prepared a project for constructing the new entrance and additional facilities following the model BOT and taking into account interest of private investors but the project has not been realised.

Public - private collaboration in Primary Health Care of the Gorenjska region was carried out with assurance of interested investors, contractual arranging of building funding as well as with realisation of activities, where private investors are partial owners of business facilities as private concessionaires or as private enterprises, where they perform activities related to health care.

For the new entrance Institute for Rehabilitation in Slovenia has chosen the system which determines that facilities and equipment come into the ownership of public partner after specific period. In this way the whole investment, leadership and maintenance of the building transfers to private partner. Such decision is reasonable, considering that in this case the concessionary private public partnership would be signed, the subject of which would be facility concession, so private partner would have to assure refunding of invested costs from renting out the business places, where the health services would be performed under the circumstances that the maximum time period for a granting of concession should be defined. Institute for Rehabilitation will guarantee realisation of the acceptable contract with private partner in public private partnership to build an integrated and functional image of the institute, offering the possibility to use the new entrance and corridor, intended for patients and visitors. In this way the quality of services would be much improved. The risk is mainly on the side of private partner, if we suppose that business facilities will have to be rented for the purpose to carry out the planned supplementary and support services successfully so that expected yield can be assured. Institute for Rehabilitation will sign concessionary public private partnership with the subject of building concession if this decision will be taken.

General Hospital Brežice has used the model of contractual funding for the project of contractual assuring of energy saving, which also contains planning and building new equipment, leading and control of functioning, service and maintenance, elimination of interferences and motivation of energy consumers.

Public-private partnership here means that planning, building, functioning and funding for specific time will be held together and the concession will be conditioned with henceforth contractual assuring of energent. Main 
Elda Gregorič Rogelj

Javno zasebno partnerstvo $v$ zdravstvu

driving force is the utilisation of private capital and risk initiative transfer, building and functioning transfer to private sector. The advantages are connected to private sector motivation for inputs, which enable larger potential for accelerated building, while bigger risk transfer means bigger motivation for the so called whole-life costing approach.

In the conditions where public health care service net has not been defined yet, the projects from the non-medical and support areas are interesting for public-private partnership, such as reconstruction and modernisation of warming systems, linen washing, cleaning, food services and other. Some individual cases of public-private partnerships have confirmed these suppositions (Institute for Rehabilitation, General Hospital Brežice) as such support and non-medicine services were performed here. Private capital investments into medical activities in public-private partnership are more demanding and claim bigger degree of health care system regulation which means that standards, normatives, nets will have to be specified by government controlling and directing.

Before entering PPP it is important to take into account the fact, that these models of collaboration are exceptionally demanding in the initiative phase as well as in the realisation phase and leading. The main guidance for public sector should be the advantage for consumer and importance of public interest as well as the consideration of legal organisational model, so that the risk would be equally balanced while at the same time the partner members have the opportunity to reach their aims.

Common investments should follow key development aims, defined in health development strategy. It is expected that government will control and play the leading role in the phase of project realisation and restoration order so that public interest will be protected.

Besides changes of law, which will arrange status and property problems and leadership spheres, also the development concept of the region is of importance.

So far existing experiences of health institutions in entering the system of private-public partnership in Slovenia confirm the fact that PPP does not represent priority choice of public service offer and it does not assure financial sources for investment inputs, nevertheless it can be an important solution because of the lack of public financial sources for investment inputs on the condition that the models of public-private partnership are well planned, led and controlled. 